\title{
Concerns about the children of psychiatric in-patients - what the parents say
}

\author{
Fiona Stormont, Tom Craig, Zerrin Atakan, Peter Loader \\ and Cindy Williams
}

There is an increasing body of research liferature investigating the effects of parental mental illness on children. This study investigates the views of psychiatric in-patients on consequences of their admission to hoepltal and their mental illness for their children. The results suggest that the parents do not readily acknowledge that their children have problems, and that interventional approaches require good liaison between adult mental health services and childfocused agencies.

Studies have consistently shown that the children of parents with severe psychiatric illness have an increased risk of a wide range of problems (as reviewed by Silverman, 1989; Quinton et al, 1990). These include an increased risk of mental illness, as well as a lower level of social and educational attainment. The cause of this increased risk is likely to be a complex combination of genetic, blological and psychosocial factors. Some risk factors such as poor communication patterns, ineffective parenting and chaotic environments may be modified by preventative interventions. However, while the literature on risk factors is extensive, relatively little has been written on the views of the parents themselves and how we manage 'risk' in terms of service development.

This pilot study investigated the views of parents in psychiatric wards about the impact of their illness and current admission on their children, with the aim of identifying a possible route for intervention with these vulnerable children. The nature of our sample means that this inquiry concerns parents with psychotic illness.

\section{The study}

The study was cross-sectional, descriptive, and based on semistructured interviews with patients in the acute psychiatric wards in West Lambeth during a 12-week period (July-October
1994). The wards are based at the South Western and St Thomas's Hospitals.

Patients who had children were asked to complete an interviewer-administered questionnaire specifically written for this study, and the psychiatric diagnosis was obtained from the medical notes. Social and demographic details were recorded, together with detalls about childcare and visiting arrangements during the current admission.

Parents were asked whether they considered their children to have any psychological problems, and about the effects of their illness and this admission on the children. They were also asked whether they ever talked to their children about their illness, and if they thought their children needed help.

\section{Findings}

Out of a total pool of 193 in-patients, 50 were parents. Thirty-two $(64 \%)$ agreed or were able to be interviewed; 21 had children aged 16 years or under. Of these, two parents had completely lost contact with their children and were therefore excluded from the results. The remaining 19 parents had a total of 36 children aged 16 years or under with whom they had contact. The results of the demographic details and psychiatric diagnoses for these 19 parents are typical for this deprived inner-city population (Table 1).

\section{Childcare arrangements}

Twelve of the 19 parents normally had full-time care of their children, and eight of these lived with a marital partner or cohabitee. During this admission, 9 of the 12 parents had children temporarily being looked after by the other parent or family members, and three had children who had been taken into the care of social services. Only two parents expressed concern about the care of their children while they were in hospital. Before their admission to 
Table 1. Demographic details

\begin{tabular}{lcc}
\hline & Number & $\%(n=19)$ \\
\hline Age & 7 & 37 \\
$<36$ & 12 & 63 \\
$>36$ & 11 & 58 \\
Gender & 8 & 42 \\
Female & 15 & 79 \\
Male & 4 & 21 \\
Employment status & 11 & 8 \\
Unemployed & 8 & 42 \\
Employed & 17 & 89 \\
Ethnic origin & 2 & 11 \\
White & & \\
Other & 1 & 5 \\
Poychiatic diagnosis & 18 & 95 \\
Psychotic & \\
Non-psychotic & & \\
Number of admissions & & \\
One & & \\
More than one & &
\end{tabular}

hospital, 7 of the 19 parents did not have fulltime care of their children (three had children who lived with relatives and four had children in care or with foster parents).

\section{Visiting arrangements}

Half (10) of the 19 parents felt that they had not been involved in any decision about their children visiting them in hospital. Twelve parents had actually received visits from their children during this admission, and of these eight had positive feelings about these visits and six thought it would have a positive effect on their children. Ten parents thought that the visiting facilities were good.

\section{Concerns about the children}

The results are shown in Table 2. Five parents believed that their children had significant psychological problems, and seven thought that they needed some sort of help. Nine parents said that their admission to hospital was bad for their children. Ten parents said that the overall effect of their illness was bad for their children. In total,
14 parents (ten women) expressed at least one concern in these four areas.

\section{Communication with the children}

Of the 19 parents, five acknowledged that at least one of their children had asked about their illness or problems, but only four had talked to them about it.

\section{Comment}

The final numbers participating in the pilot study were small, and this means that the results need to be interpreted with caution. Unlike Wang \& Goldschmidt (1994), who found the patients easy to approach as parents, we found the degree of participation disappointing but not surprising in an inner-city service that deals almost exclusively with psychotic illness. Patients who were thought to be too unwell when initially approached were interviewed when they were more settled. Inevitably this resulted in some patients being missed from the study. Single young men form a large proportion of the in-patients in this catchment area, perhaps explaining the relatively low proportion of parents in this study.

It is important to bear in mind that the majority of children with mentally ill parents do not become ill themselves (Rutter, 1985). However the frequent episodes of severe mental illness in the parents in our study suggest that their children have a higher than normal risk of problems (Silverman, 1989).

The majority of the mentally ill parents with children in our sample were normally responsible for their full-time care, although most of them shared this task with a marital partner or cohabitee. This finding highlights the need for routine recording, often not done in our experience, of the family circumstances of adult psychiatric patients, including details of any children and their care. The first step in providing help for these vulnerable children must be their reliable identification by adult services.

Although only a small number of the parents acknowledged that their children had 'psychological problems' or needed help, more could appreciate the negative effects of their admission

Table 2. Concerns about children

\begin{tabular}{lccc}
\hline & Yes & No & Parent unclear \\
\hline Children have psychological problems & 5 & 12 & 2 \\
Parent's illiness bad for children & 10 & 6 & 3 \\
Parent's admission bad for children & 9 & 6 & 4 \\
Children neөd help & 7 & 12 & 0 \\
Parents concerned in any one of these areas & 14 & 5 & 0 \\
\hline
\end{tabular}


and illness. The interviewers had the distinct impression that the parents found it generally difficult to acknowledge the impact of their illness on their children. Without more information on the children, including the views of other family members and the children themselves, it is impossible to tell how well the ill parent's opinion ties up with the child's reality. We simply do not know how many of the children actually had problems, but previous work in this area would suggest a higher proportion (30-70\%) than that perceived by the parents in our study.

Our study highlights particular problems in supporting this group of children. We cannot assume that they have, or will have, psychiatric problems themselves but we know that they are 'at risk' and that those children who are having problems may easily go unnoticed. Preventative interventions, including education and support for the ill parent and other family members, should be part of routine psychiatric practice, but we also need to develop more reliable ways of identifying those children who are in trouble in order to offer early intervention.

The question remains as to how to promote such good practice. One important initiative might be suggested, not by the results of this study, but how it was carried out. This was a joint enterprise, requiring collaboration and cooperation from start to finish between the departments of child psychiatry and adult psychiatry. While this proved an amicable and enjoyable liaison, it also revealed how little the two services normally had to do with each other. This lack of connection is not unusual but is puzzling given that the most obvious distinction between the services is the age of the client. Adult psychiatrists are constantly dealing with disturbed parents, and child psychiatrists are well aware of the risks to the children and how to identify signs of distress. The children of mentally ill parents therefore pose a problem that requires close links between adult and child mental health services, or they can all too easily fall into the gap between them. This liaison must also include a close working relationship with social services via the social worker attached to the ward. These children are a shared concern and our response must be a working-together that allows their difficulties to be appreciated and their needs to be met. We would argue that this is often palpably not the case, and that our efforts to help must include the development of more effective liaison between adult and child mental health services.

\section{References}

QUINTON, D., RUTTER, M. \& GULJVER, L. (1990) Continuities in psychiatric disorders from childhood to adulthood. In Straight and Devious Pathways from Childhood to Adulthood (eds L. Robins \& M. Rutter). New York: Cambridge Untversity Press.

RUTTER, M. (1985) Resilience in the face of adversity: protective factors and resistance to psychiatric disorders. British Journal of Psychiatry. 147, 598-611.

SILVERMAN, M. (1989) Children of psychiatrically ill parents: a prevention perspective. Hospital and Community Psychiatry. 40, 1257-1265.

WANG, A. \& GoLDSchmid, V. V. (1994) Interviews of psychiatric inpatients about their family situation and young children. Acta Psychiatrica Scandinavica, 80. 459-465.

Fiona Stormont, Registrar, Department of Psychiatry, United Medical and Dental School, Guy's Hospital, London SE1 9RT, Tom Craig, Professor of Community Psychiatry, UMDS Division of Psychiatry. St Thomas's Hospital, London; Zerrin Atakan, Honorary Senior Lecturer and Consultant Psychiatrist, Lambeth Healthcare Trust, South Western Hospital, Stockwell, London; *Peter Loader, Sentor Lecturer and Honorary Consultant in Child Psychiatry, UMDS and Lambeth Healthcare Trust, 35 Black Prince Road, Kennington, London SE11 6JJ; and Cindy Williams, Clinical Nurse Specialist, Department of Child and Family Psychiatry, Lambeth Healthcare Trust, London

*Correspondence 